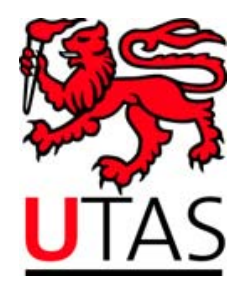

SCHOOL OF ECONOMICS AND FINANCE

Discussion Paper 2013-15

\title{
Equity Market Contagion during the Global Financial Crisis: Evidence from the World's Eight Largest Economies
}

Mardi Dungey and Dinesh Gajurel 


\title{
Equity Market Contagion during the Global Financial Crisis: Evidence from the World's Eight Largest Economies
}

\author{
Mardi Dungey*ł‡ and Dinesh Gajurel ${ }^{\S}$
}

May 2013

\begin{abstract}
The global financial crisis (2007-2009) saw sharp declines in stock markets around the world, affecting both advanced and emerging markets. In this paper we test for the existence of equity market contagion originating from the US to advanced and emerging markets during the crisis period. Using a latent factor model, we provide strong evidence of contagion effects originating in US equity markets to equity markets in both the advanced and emerging economies. In the aggregate equity market indices contagion from the US explains a large portion of the variance in stock returns in both advanced and emerging markets. However, evidence from the financial sector indices finds less evidence of contagion than the total indices, and this is particularly the case for the developed markets. This suggests that contagion effects are not strongly related to high levels of global integration.
\end{abstract}

Keywords: Global financial crises, financial contagion, financial markets, advanced countries, emerging countries

JEL classification: F30, F36, F62, G12, G15 G20

*School of Economics and Finance, University of Tasmania, Australia. Mardi.Dungey@utas.edu.au

${ }^{\dagger}$ CAMA, Australian National University, Australia

${ }^{\ddagger}$ CFAP, University of Cambridge, UK

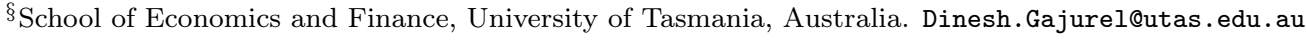




\section{Introduction}

The global financial crisis (GFC), which began with the US real estate bubble burst in 2007, quickly led to a sharp decline in stock market indices in the US and across global financial markets - both advanced and emerging. Over the crisis period (from July 2007 to May 2009), the US equity market alone lost about 40 percent of its market capitalization. The loss is even higher for some other countries. For example, the UK equity market lost about 49 percent and the Russian equity market lost about 52 percent. At a sectoral level, the financial sectors around the world experienced even greater losses (in percentage points). The US financial sector experienced an approximately 60 percent loss in its market capitalization, the UK financial sector lost about 66 percent, and the Russian financial sector lost about 70 percent. These facts show the severe impact of the global financial crisis on financial markets around the world.

An important question is whether this increased comovement of global financial markets during the 2007-2009 crisis provides evidence of contagion. Defining contagion as a significant increase in cross-country comovement of asset returns, we test for the existence of contagion and measure contagion effects running from the US to both advanced and emerging markets. The focus of our analysis is on the aggregate equity market in general and the financial sector in particular.

We take the latent factor approach of Dungey et al. (2005) which nests several other empirical approaches (Bekaert and Harvey, 1995; Forbes and Rigobon, 2002; Corsetti et al., 2005) in an unifying framework to test for contagion. Our sample consists of the US (as a crisis originating country) and eight other large economies in terms of GDP (the four largest advanced economies France, Germany, Japan and the UK; and the four largest emerging economies - Brazil, China, India and the Russia). We use a relatively large sample period (daily returns data from 2004 to 2010) and determine crisis and non-crisis periods using an Iterative Cumulative Sum of Square (ICSS) approach (Inclan and Tiao, 1994; Sanso et al., 2004).

Our results provide strong evidence of contagion effects from the US equity market to equity markets in both advanced and emerging markets. Contagion from the US explains a large portion of the variance in stock returns in advanced and emerging economies. However, there is less contagion effect in financial sector stocks than in the aggregate equity market, particularly in advanced economies. The results for the financial sector cast doubt on the financial globalization hypothesis - that is, whether contagion during the crisis has a greater effect on those markets that are highly 
integrated. Overall, our results are consistent with previous studies on equity market contagion during the GFC(Bekaert et al., 2011; Baur, 2012). However, unlike Bekaert et al. (2011), we find large contagion effects in equity markets.

The rest of the paper is organized as follows. Section 2 reviews the literature on financial contagion; Section 3 explains the latent factor model, sample and data, and empirical model specification; results and discussion are presented in Section 4; and Section 5 concludes the paper

\section{Literature Review}

\subsection{Defining financial contagion}

There is no unanimously accepted definition of financial contagion, and is closely tied to the statistical definition of how the spread of market disturbances is measured. ${ }^{1}$ The World Bank summarizes three layers within contagion definations. ${ }^{2}$ In a broad sense, contagion is the cross-country transmission of shocks or the general cross-country spillover effects. In a restrictive sense, contagion is the transmission of shocks to other countries, or the cross-country correlation, beyond any fundamental link among the countries and beyond common shocks. In a very restrictive sense, contagion refers to increase in cross-country correlations during "crisis times" relative to correlations during "tranquil times." The very restrictive definition is commonly used in recent empirical analysis to identify and measure financial contagion (Forbes and Rigobon, 2002; Dungey et al., 2005, among others). This paper follows this convention.

\subsection{Mechanisms of crises transmission}

The literature includes two groups of theories, which are not necessarily mutually exclusive, explaining crisis transmission mechanisms. One group argues that the economic fundamentals of different countries are interconnected by their cross-border flows of goods, services, and capital. When a crisis originates in one country, this interdependence of economies through real and financial linkages becomes a carrier of crisis (Kaminsky and Reinhart, 1998; Glick and Rose, 1999; Rijckeghem and

\footnotetext{
${ }^{1}$ For example, Eichengreen et al. (1996) define contagion as a significant increase in the probability of a crisis in one country, conditional on a crisis observed in an origin country. Hamao et al. (1990) refer to contagion as a volatility spillover from crisis country to other countries. Forbes and Rigobon (2002) and Dungey et al. (2005), among others, refer to contagion as a significant increase in the co-movements of prices across markets conditional on a crisis occurring in one market or a group of markets.

${ }^{2}$ http://go.worldbank.org/JIBDRK3YC0
} 
Weder, 2001). In addition, global phenomena or common shocks such as a major economic shift in industrial countries, significant changes in oil prices, changes in US interest rates, and changes in exchange rates may adversely affect the economic fundamentals of several economies simultaneously, therefore may cause a crisis (Eichengreen et al., 1996). These fundamental based effects are also known as 'spillovers' (Masson, 1999), 'interdependence' (Forbes and Rigobon, 2002), or 'fundamentals based contagion' (Kaminsky and Reinhart, 1998).

Another group of theories argues that financial crisis spreads from one country to another due to market imperfection or the behavior of international investors (Diamond and Dybvig, 1983; King and Wadhwani, 1990; Masson, 1999; Dornbusch et al., 2000; Kodres and Pritsker, 2002). Information asymmetries make investors more uncertain about the actual economic fundamentals of a country. A crisis in one country may give a "wake-up call" to international investors to reassess the risks in other countries, and uninformed or less informed investors may find it difficult to extract the informed signal from the falling price, and follow the strategies of better informed investors generating excess co-movements across the markets (Goldstein, 1998; Yuan, 2005; Pasquariello, 2007). Tthe degree of (non)anticipation of a crisis by investors is crucial for existence of contagion because of investors' attention allocation (Mondria and Quintana-Domeque, 2012). Sudden shifts in market confidence and expectations have been identified as important factors causing contagion (Masson, 1999; Mondria and Quintana-Domeque, 2012).

The initial empirical literature on financial crisis and contagion focused on fundamentals-based mechanisms and directed towards developing an early warning system (Eichengreen et al., 1996; Kaminsky et al., 1998; Rijckeghem and Weder, 2001) while later empirical works are focused on investor behavior based mechanisms Dungey et al. (2005); Bekaert et al. (2011).

In an early and influential study, King and Wadhwani (1990) examine the correlation between US, UK and Japanese stock markets during the 1987-1988 (stock market crash in 1987). They find evidence of increased correlation between the US, UK, and the Japanese stock markets during the 1987 crisis which cannot be explained by economic fundamentals. Baig and Goldfajn (1999) use a similar approach to examine financial contagion in Asian markets during the Asian crisis and find that the correlation across the countries for same asset class (stock markets, interest rates, sovereign bond spreads and exchange rates) increased significantly during the crisis period.

In a seminal paper, Forbes and Rigobon (2002) provide a breakthrough on the conventional correlation analysis approach for testing contagion. As volatility increases during a crisis, an increase 
in correlation may simply be a continuation of strong transmission mechanisms that exist in more stable periods. Forbes and Rigobon (2002) offer an adjusted correlation coefficient approach to test for contagion in 28 stock markets and three episodes of crisis. They conclude that the observed increase in correlation during crisis period is due to increased interdependence among the markets, not contagion.

In a slightly different fashion, Dungey and Martin (2001); Bekaert et al. (2005); Corsetti et al. (2005); Bekaert et al. (2011), among others, follow a factor model of correlation analysis to test for contagion during different episodes of financial crises.

There is a growing body of empirical literature testing for financial contagion during the GFC. Using a broad set of data from 55 advanced and emerging countries, Bekaert et al. (2011) examine the transmission of crises to country-industry equity portfolios in 55 countries during the global financial crisis. Using a CAPM based approach, they find systematic and substantial contagion from domestic equity markets to individual domestic equity portfolios, with its severity inversely related to the quality of countries' economic fundamentals. They consequently find a small evidence of contagion running from US markets and from the global financial sector. Therefore, conclude that investors focus substantially more on country-specific characteristics (idiosyncratic risks) during the crisis period. However, in a slightly different empirical setting, Baur (2012) also uses the sectoral level data from 25 countries (industrial and developing) and examines the spread of financial crises from the financial sector to real sector within a country and across countries during the crisis. He finds strong contagion effects and claims that no region or specific group of countries has been immune to shocks associated with crisis, however, real economy sectors especially healthcare, telecommunication and IT sector were less contagious.

A stylized fact of the GFC is that financial markets around the world suffered from tremendous loss. However, there still remain disagreements on the international transmission of the crisis and its mechanisms. In particular, whether this international transmission of crisis resulted from interconnected global markets (through real and financial linkages) or was caused by the idiosyncratic factors (attributed to behaviors of market participants during the crisis period). The divergent empirical findings on contagion tests largely depend on how the crisis transmission channel is defined and how it is implemented in an empirical setting (Dungey et al., 2005). The different and even inconsistent findings of studies using different empirical approaches make it difficult to compare results and therefore to reach into a meaningful conclusion. Dungey et al. (2005) nest the empirical framework 
of Forbes and Rigobon (2002); Bae et al. (2003); Corsetti et al. (2005) and Bekaert et al. (2005) and provide a simple and unifying framework to test for contagion which is adopted in Section 3.

\section{Empirical Framework}

\subsection{Latent factor model}

The latent factor model of Dungey et al. (2005) is based on the Capital Assets Pricing Model (CAPM) framework. Let the return on an asset, $y_{i, t}$, during the non-crisis period be a function of a common factor, $w_{t}$ which affects all the asset markets, and an idiosyncratic factor, $u_{i, t}$ which is specific to a particular asset market. The relationship can be expressed as:

$$
y_{i, t}=\lambda_{i} w_{t}+\delta_{i} u_{i, t} ; i=1,2, \ldots, N
$$

where $i$ refers to the market $i$, and $t$ refers to time. The $\lambda_{i}$ and $\delta_{i}$ refer to factor loadings of common factor and idiosyncratic factors respectively. The factors are assumed to be latent stochastic processes with zero mean and unit variance. The factors are orthogonal to each other, and the covariance of idiosyncratic factors across different markets is assumed to be zero:

$$
\begin{gathered}
w_{t} \sim i . i . d .(0,1) \\
u_{i, t} \sim i . i . d .(0,1) \\
E\left[w_{t} u_{i, t}\right]=0 \forall i \\
E\left[u_{i, t} u_{j, t}\right]=0 \forall i \neq j .
\end{gathered}
$$

Therefore, for the pre-crisis period, the unconditional variance and covariance of $y_{i, t}$ can be expressed as:

$$
\begin{gathered}
E\left[y_{i}^{2}\right]=\lambda_{i}^{2}+\delta_{i}^{2}(i=1,2, \ldots N) \\
E\left[y_{i}, y_{j}\right]=\lambda_{i} \lambda_{j}(i=1,2, \ldots N) \forall i \neq j,
\end{gathered}
$$

Assume that a crisis originates in the first market via an idiosyncratic shock. During the crisis period, the idiosyncratic factor of the first market may affect the returns on assets in other markets 
in a way which does not occur during the non-crisis period. Dungey et al. (2005) identify this avenue as a contagion channel. Therefore, during the crisis period, the return on asset in each market can be expressed as:

$$
\begin{gathered}
y_{1, t}=\lambda_{1} w_{t}+\delta_{1} u_{1, t} \\
y_{j, t}=\lambda_{j} w_{t}+\delta_{j} u_{2, t}+\varphi_{1, j} u_{1, t} ; j=2, \ldots, N .
\end{gathered}
$$

If we allow contemporaneous shocks across the markets, then Eq. (8) and (9) can be expressed as:

$$
y_{i, t}=\lambda_{i} w_{t}+\delta_{i} u_{i, t}+\sum_{j=1, i \neq j}^{N} \varphi_{i, j} u_{j, t} ; i=1, \ldots, N .
$$

Now the test of contagion relies on the statistical significance of the $\psi_{i, j} \mathrm{~s}$. If the $\psi_{i, j} \mathrm{~s}$ are significantly different from zero, there is a contagion effect.

For the crisis period, as in Eq. (6), the variance of $y_{i, t}$, based on Eq (10) can be expressed as:

$$
E\left[y_{i}^{2}\right]=\lambda_{j}^{2}+\delta_{i}^{2}+\sum_{i=1, i \neq j}^{N} \varphi_{i, j}^{2}(i=1,2, \ldots N) .
$$

The contribution of each factor can be represented as the proportion of volatility of $y_{i}$ explained by common shocks, idiosyncratic factor, and contagion respectively:

$$
\frac{\lambda_{i}^{2}}{\lambda_{i}^{2}+\delta_{i}^{2}+\sum_{i=1, i \neq j}^{N} \varphi_{i, j}^{2}} ; \frac{\delta_{i}^{2}}{\lambda_{i}^{2}+\delta_{i}^{2}+\sum_{i=1, i \neq j}^{N} \varphi_{i, j}^{2}} ; \frac{\varphi_{i, j}^{2}}{\lambda_{i}^{2}+\delta_{i}^{2}+\sum_{i=1, i \neq j}^{N} \varphi_{i, j}^{2}}
$$

Eq. (12) provides the descriptive measure of the relative strength of contagion in contributing to the volatility of returns during the crisis period. In this way, the latent factor approach of Dungey et al. (2005) provides not only a test for contagion but also a measure of the relative strength of contagion explaining market volatility.

\subsection{Sample and Data}

Along with the US as the crisis origin country, we focus on four major advanced economies (France, Germany, Japan and UK) and four major emerging economies (Brazil, Russia, India and China) to examine the international transmission of the crisis. The selection of these countries is based on their size (in terms of gross domestic product, GDP) and their economic/market structure. The five advanced economies are the largest five countries from the advanced economy group and the four 
emerging economies are the largest four countries from the emerging economy group as classified by International Monetary Fund. ${ }^{3}$ In addition, these nine markets together make up about 62.1 percent of world GDP (authors' calculation based on 2010 GDP in current US Dollar). ${ }^{4}$

Our sample period covers from January 02, 2004 to December 31, 2010. We use daily data extracted from Thompson Reuters Datastream, and compute daily returns as the log difference of the daily price index. To overcome the geographical time differences problem (among the sample economies), we use Day 01 in US and Brazil = Day 02 in European and Asian markets markets. We also performed sensitivity analysis by using a two-day moving average (as in Forbes and Rigobon (2002)), as well as data without time adjustment. The results are robust to these changes.

\subsection{Identifying crisis dates}

The empirical literature on financial contagion suggests that the results are sensitive to the data windows and choice of crisis date (Dungey et al., 2005). Correlation based studies often rely on exogenously determined crisis dates. In this paper, we use endogenously determined crisis and non-crisis periods. We use an Iterative Cumulative Sum of Square (ICSS) algorithm based on the CUSUM test to detect the structural change in variance of an individual return series (Inclan and Tiao, 1994; Sanso et al., 2004) and first applied to crisis period detection by Wang and Nguyen Thi (2012). The ICSS approach assumes that return series exihibit a stationary variance over an initial period until a sudden change in variance occurs and then stationary again for a time until the next sudden change. This process is repeated through time, yielding a number of changes in the variance (Aggarwal et al., 1999).

Let's consider the demeaned asset return series, $\varepsilon_{t}$, which is normally distributed with $\sigma_{t}^{2}$. For the whole sample of $T$ observations, the variance within each interval is denoted by $\tau_{j}^{2}, j=0,1, \ldots N_{T}$, and $1<k_{1}<k_{2}<\ldots<k_{N_{T}}<T$ are the dates of break in variance,

$$
\begin{aligned}
\sigma_{t}^{2}= & \tau_{0}^{2} ; \text { if } 1<t<k_{1}, \\
= & \tau_{1}^{2} ; \text { if } k_{1}<t<k_{2} \\
& \ldots \\
= & \tau_{N_{T}}^{2} ; \text { if } k_{N_{T}}<t<T .
\end{aligned}
$$

\footnotetext{
${ }^{3}$ http://www.imf.org/external/pubs/ft/weo/2010/02/weodata/weoselgr.aspx, accessed on 15/04/2012.

${ }^{4}$ http://data.worldbank.org/indicator/NY.GDP.MKTP.CD, accessed on 15/04/2012.
} 
Table 1: Structural breaks in volatility in the US equity and financial index reruns

\begin{tabular}{lllll}
\hline SN & Description & Equity & Finance & Remarks \\
\hline 1 & First break & July 19, 2007 & July 19, 2007 & Crisis period begins \\
\hline 2 & Second break & September 12, 2008 & July 4, 2008 & Heightened period \\
\hline 3 & Third break & June 1, 2009 & May 29, 2009 & Crisis period ends \\
\hline 4 & Fourth break & September 3, 2010 & December 12, 2010 & Post crisis period ends \\
\hline
\end{tabular}

To estimate the number of changes in variance and the point in time of each variance shift, Inclan and Tiao (1994) define a $D_{k}$ statistic as follows:

$$
D_{k}=\frac{C_{k}}{C_{T}}-\frac{k}{T} ; \quad k=1, \ldots, T \mid D_{0}=D_{t}=0
$$

where, $C_{k}=\sum_{t=1}^{k} \epsilon_{t}^{2}, k=1, \ldots, T$ is the cumulative sums of squares of $\epsilon_{t}$ from the beginning of the series to $k^{t h}$ point in time. If there are no changes in variance over the sample period, the $D_{k}$ statistic oscillates around zero and asymptotically, behaves as a standard Brownian motion (Inclan and Tiao, 1994). ${ }^{5}$ If there are one or more sudden variance changes in the series, the $D_{k}$ values drift either up or down from zero (Aggarwal et al., 1999). ${ }^{6}$ Sanso et al. (2004) offer modifications to the ICSS algorithm incorporating heteroskedasticity and fourth moment properties of financial data. They replace $D_{k}$ by $G_{k}=\tilde{\omega}_{4}\left(C_{k}-\frac{k}{T} C_{T}\right)$, where $\tilde{\omega_{4}}$ is a consistent estimator of $\omega_{4}$, the long-run fourth moment of $\epsilon_{t}$ (Sanso et al., 2004). ${ }^{7}$ The null hypothesis of no break in variance is rejected when $G_{k^{*}}=\operatorname{Max}_{k}\left(\left|T^{-0.5} G_{k}\right|\right)$ is outside the confidence interval range. The simulation based critical value (at $\alpha=5 \%$ ) for $G_{k^{*}}$ is 1.406 .

Table 1 provides the results for the ICSS test to our sample. The break dates are approximately equivalent to GFC period defined by the World Bank (BIS, 2009); and the US recession end date defined by the National Bureau of Economic Research (NBER, 2010). Since the crisis began in the financial sector, we choose the financial sector break dates. Therefore crisis period considered in this paper is from July 19, 2007 to May 29, 2009.

\footnotetext{
${ }^{5}$ This can be observed by plotting $D_{k}$ values against $k$.

${ }^{6}$ See Inclan and Tiao (1994) for more detail on ICSS algorithm.

${ }^{7}$ The non-parametric estimator of $\omega_{4}$ is:

$$
\tilde{\omega}=\frac{1}{T} \sum_{t=1}^{T}\left(\epsilon_{t}^{2}-\tilde{\sigma}^{2}\right)^{2}+\frac{2}{T}\left(\sum_{l=1}^{m} \omega(\iota, \omega) \sum_{t=l+1}^{T}\left(\epsilon_{t}^{2}-\tilde{\sigma}^{2}\right)^{2}\left(\epsilon_{t-l}^{2}-\tilde{\sigma}^{2}\right)^{2}\right.
$$
}

where $\omega(\iota, \omega)$ is a Bartlett window and $\tilde{\omega}_{4}$ estimate depends on the choice of $m$ parameter with the Newey-West method (Sanso et al., 2004). 


\subsection{Stylized facts and descriptive statistics}

Unlike other financial crises ${ }^{8}$ which were often regional in nature and lasted for a relatively short period of time, the GFC lasted for about two years. This crisis affected both the advanced economies and emerging economies in our sample. As revealed in Figure 1 and 2, before the crisis, the equity market indices of these economies were increasing gradually. When the crisis hit over the period from July 2007 to May 2009, the US equity market alone lost about 40 percent of its market capitalization; the French equity market lost about 46 percent; the German equity market lost about 41 percent; the Japanese equity market lost about 35 percent; and the UK equity market lost about 49 percent. The magnitude of the crisis effect in emerging markets, however, is relatively lower. For example, China, India, and Brazil lost equity market capitalization by about 23,24 , and 25 percent respectively. The Russian equity market lost the most at about 52 percent.

The effect of crisis is more severe in the financial sector. The US financial sector lost about 60 percent of market capitalization whereas the French, German, and Japanese financial sectors lost about 58 percent, 50 percent and 45 percent respectively, and the UK financial sector experienced the highest loss (about 66 percent) among the advanced economies. The loss figures for the financial sector are about 10 to 20 percent above the loss in the overall equity markets for each country. In the case of emerging economies, except for Russia, the loss faced by the financial sector is about 30 percent. The Russian financial sector experienced an approximate 70 percent loss in its market capitalization during the global financial crisis which is the highest loss among all the markets investigated. All these markets experienced negative returns over the crisis period, and their market volatility (standard deviation) approximately doubled compared with the non-crisis period. US financial sector volatility increased by approximately 4 fold. These facts indicate the severity of this crisis. Figures 3 and 4 depict the daily returns for advanced and emerging markets.

\footnotetext{
${ }^{8}$ Mexican crisis, Asian crisis, Russian crisis, LTCM collapse, Dot com bubble etc.
} 
Figure 1: Aggregate equity market price index for advanced countries

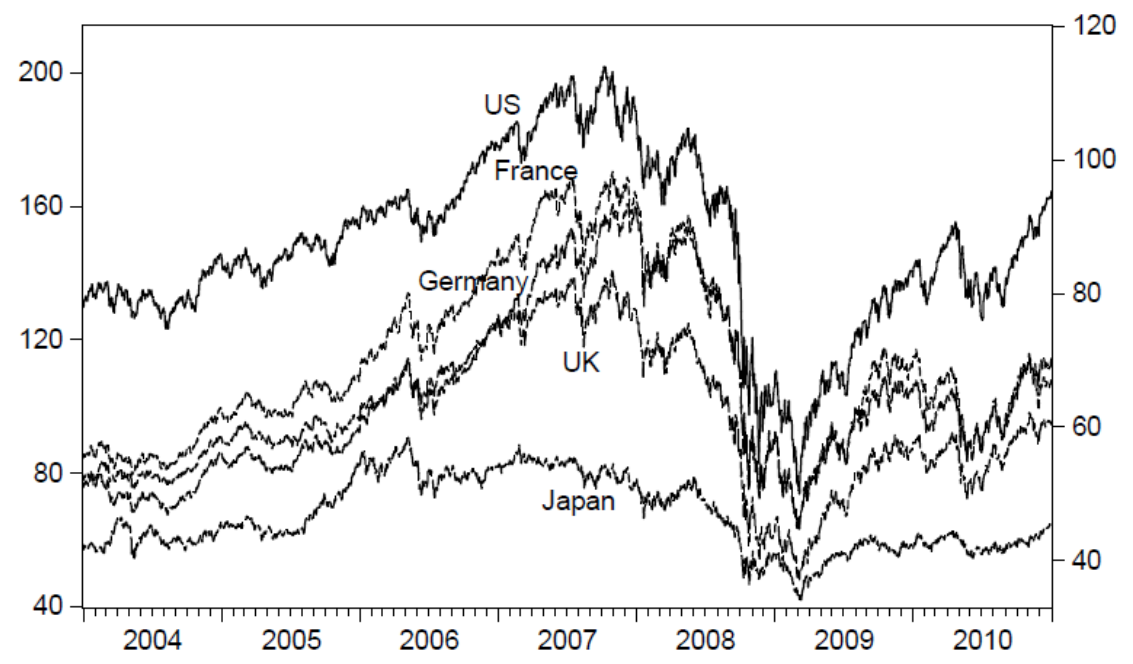

Note: The right hand side scale applies to US and left hand side scale applies to rest. The price index is measured in US dollars and re-indexed to 100 on January 1, 2000. Data source: Thompson Reuters Datastream.

Figure 2: Aggregate equity market price index for emerging countries and the US

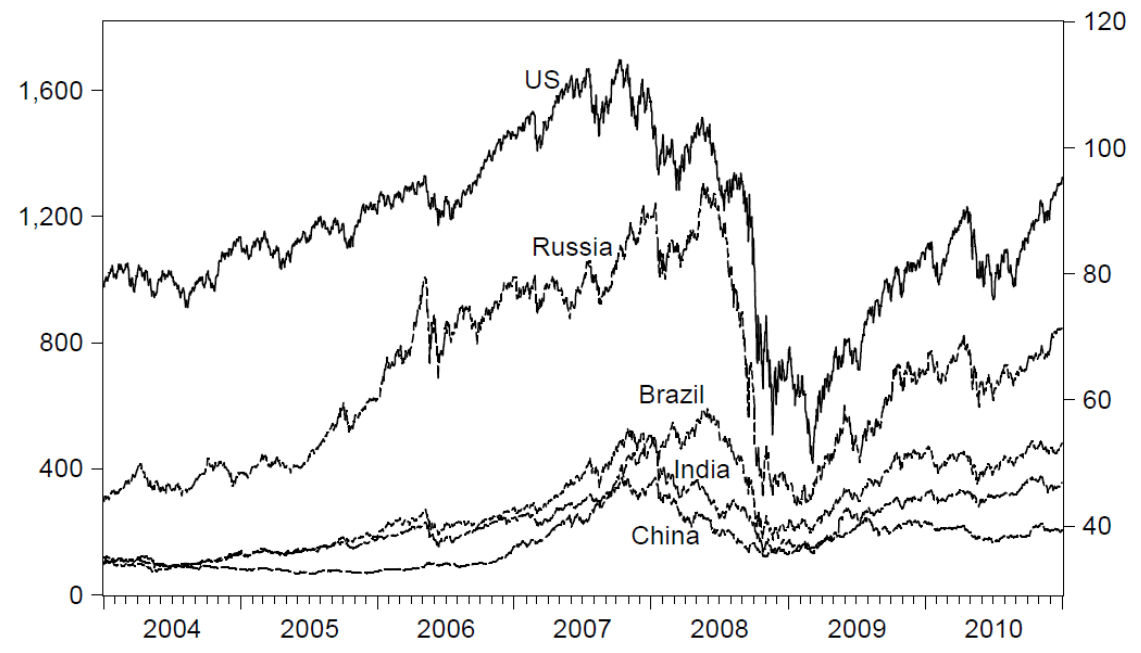

Note: The right hand side scale applies to US and left hand side scale applies to rest. The price index is measured in US dollars and re-indexed to 100 on January 1, 2000. Data source: Thompson Reuters Datastream.

The descriptive statistics in Table 2 reveal that while emerging markets experienced relatively lower negative returns than advanced markets during the crisis period, emerging markets were relatively more volatile than advanced markets at the same time. During the non-crisis period, the emerging markets had higher returns than advanced markets. Furthermore, in advanced economies, 


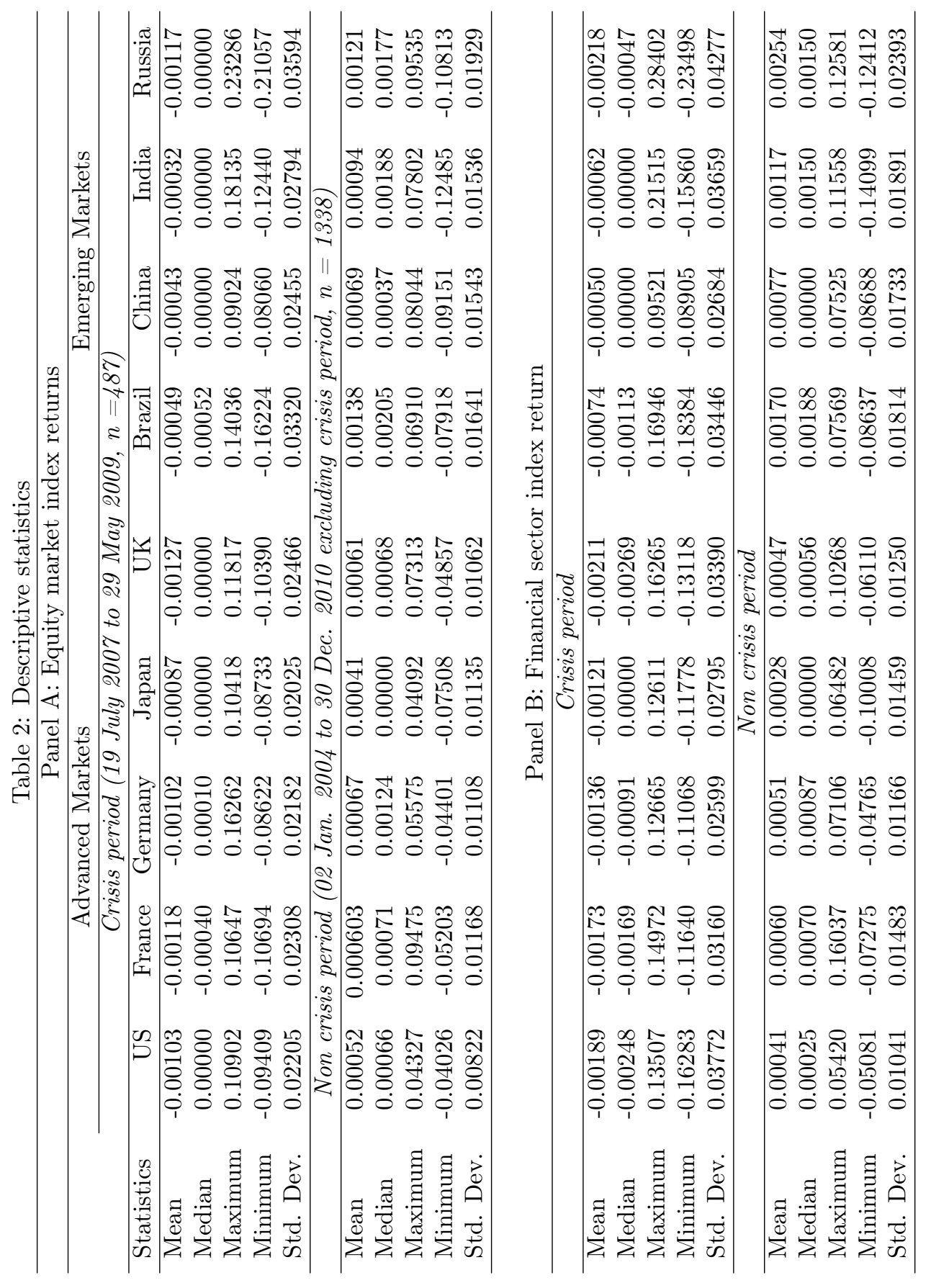


the overall equity market portfolio has higher returns than the financial sector portfolio, whereas in the emerging markets, the financial sector portfolio has higher returns than the aggregate equity market portfolio. The higher performance of the financial sector in emerging markets could be attributed to banking oriented capital markets, less market competition, and higher economic growth in these economies.

\subsection{Empirical model specifications}

Our empirical setting relies on the factor model specification of Dungey et al. (2005) as shown in Eq. (8) and (9). The crisis first originated in the US market and subsequently spread to other markets. We examine US contagion effects in advanced economies and emerging economies separately to achieve exact identification. In a five markets case, there are 15 moment conditions. We have five $\lambda$ s and five $\delta$ s. Therefore, we have a maximum of five contagion channels which be identified with the model. In the actual empirical setting, we define four contagion channels from the US to each of four other countries and we use one additional parameter to check for a structural break in the US common factor. Therefore, our empirical framework proceeds as follows:

$$
\begin{aligned}
& {\left[\begin{array}{c}
y_{U S, t} \\
y_{2, t} \\
y_{3, t} \\
y_{4, t} \\
y_{5, t}
\end{array}\right]=\underbrace{\left[\begin{array}{c}
\lambda_{1} \\
\lambda_{2} \\
\lambda_{3} \\
\lambda_{4} \\
\lambda_{5}
\end{array}\right]\left[\begin{array}{l}
w_{t}
\end{array}\right]+\operatorname{diag}\left[\begin{array}{c}
\delta_{1} \\
\delta_{2} \\
\delta_{3} \\
\delta_{4} \\
\delta_{5}
\end{array}\right]\left[\begin{array}{l}
u_{1, t} \\
u_{2, t} \\
u_{3, t} \\
u_{4, t} \\
u_{5, t}
\end{array}\right]}_{\text {Common }}}
\end{aligned}
$$

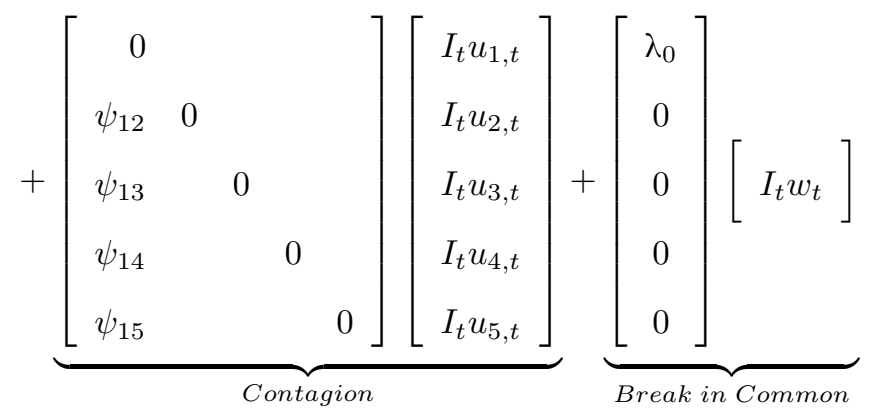

where $I$ is an indicator function that takes value 1 during the crisis period, otherwise 0 . The loading matrix for the idiosyncratic factor in Eq. (16) can be altered for the possible contagion channels across the markets including feedback to the US market but the choice of contagion channel is limited 
by number of available moment conditions and number of parameters to be estimated. ${ }^{9}$

We take generalized method of moments (GMM) approach to estimate the parameters in Eq. (16). We follow Dungey et al. (2005) and use indirect estimation technique by matching the theoretical and empirical moment conditions.

For the non-crisis period, the variance-covariance structures of markets take the same form as in Eq. (4) and (5). For the crisis period, the variance-covariance structure of markets can be expressed as:

Variance of the US market:

$$
E\left[y_{U S}^{2}\right]=\lambda_{1}^{2}+\delta_{1}^{2}+\lambda_{0}^{2} .
$$

Variance of other markets:

$$
E\left[y_{i}^{2}\right]=\lambda_{i}^{2}+\delta_{i}^{2}+\psi_{1 i}^{2} ; \quad i=2, \ldots, 5 \neq U S .
$$

Covariance between the US and each of other markets :

$$
E\left[y_{U S}, y_{i}\right]=\lambda_{1} \lambda_{i}+\delta_{1} \psi_{1 i} ;=2, \ldots, 5 \neq U S \text {. }
$$

Covariance between other markets:

$$
E\left[y_{i}, y_{j}\right]=\lambda_{i} \lambda_{j}+\psi_{1 i} \psi_{1 j} ; \quad i=2, \ldots, 5 \forall i \neq j \neq U S
$$

The non-crisis and crisis period variance-covariance conditions in can be obtained by introducing indicator function $(I)$ in Eq. (17) to (20) as indicated in Eq. (16).

We decompose the variance of each market as a proportion contribution of each factor in Eq. (16) as specified in Eq. (12), (17), and (18). More specifically, for the non-crisis period, the proportion contributed by common factor for each market $(i)$ is given by:

$$
\lambda_{i}^{2} /\left(\lambda_{i}^{2}+\delta_{i}^{2}\right)
$$

and the proportion contributed by idiosyncratic factor is given by:

\footnotetext{
${ }^{9}$ Our preliminary analysis of Granger Causality tests indicates that the US market is not Granger caused by other markets.
} 


$$
\delta_{i}^{2} /\left(\lambda_{i}^{2}+\delta_{i}^{2}\right)
$$

For the crisis period, for the US, the proportion contributed by common factor is given by:

$$
\left(\lambda_{1}^{2}+\lambda_{0}^{2}\right) /\left[\left(\lambda_{1}^{2}+\lambda_{0}^{2}\right)+\delta_{1}^{2}\right]
$$

and the proportion contributed by idiosyncratic factor is given by:

$$
\delta_{1}^{2} /\left[\left(\lambda_{1}^{2}+\lambda_{0}^{2}\right)+\delta_{1}^{2}\right]
$$

For other markets, the proportion contributed by common factor is given by:

$$
\lambda_{i}^{2} /\left(\lambda_{i}^{2}+\delta_{i}^{2}+\varphi_{1, i}^{2}\right) ; \quad i=2, \ldots, 5 \forall i \neq U S
$$

the proportion contributed by idiosyncratic factor is given by:

$$
\delta_{i}^{2} /\left(\lambda_{i}^{2}+\delta_{i}^{2}+\varphi_{1, i}^{2}\right)
$$

and the proportion contributed by contagion factor is given by:

$$
\varphi_{1, i}^{2} /\left(\lambda_{i}^{2}+\delta_{i}^{2}+\varphi_{1, i}^{2}\right) .
$$

The variance decomposition outlined above provides the relative strength of each factor for a given market contributing to its market volatility.

We test the overall significance of the model specified in Eq. (18) using Hansen's $J$-test for a number of overidentification restrictions where the $J$ statistic is:

$$
J=T Q
$$

where $T$ is the sample size, and $Q$ is the value of objective value function of the GMM estimator which takes of the form:

$$
Q=M^{\prime} W^{-1} M
$$


where $M$ is a vector containing the difference between the empirical and theoretical moments and $W$ is the optimal weighting matrix. The $J$ statistic is distributed asymptotically $\chi^{2}$ with $\vartheta$ (number of restricted parameters) degrees of freedom. Under the null hypothesis, the restrictions are set to be zero. If the value of $J$ statistic is below the the $\chi^{2}$ critical value at 5 percent level of significance for given level of degrees of freedom, the null hypothesis of "the model is valid with restrictions" is accepted.

For a joint test of contagion using factor model in Eq. (16), we perform an LR test with 4 degrees of freedom under the null hypothesis $\left(\varphi_{1, j}=0\right)$. This test of contagion can be interpreted as testing for changes in both variances and covariances (Dungey et al., 2005).

\section{Results}

\subsection{Model restrictions and statistical significance}

The model in Eq. (18) is exactly identified with 15 parameters and 15 moment conditions. We further test the model by imposing restrictions on (i) contagion parameters and parameter for a break in the US common factor, $\left(\varphi_{1, j}=\lambda_{0}=0\right)$; (ii) parameter for a break in the US common factor $\left(\lambda_{0}=0\right)$ only; and (iii) contagion parameters, $\left(\varphi_{1, j}=0\right)$ only. We used Hansen's $J$-test for overidentification when restrictions were imposed. The results are reported in Panel A of Table 3.

The restrictions $\varphi_{1, j}=\lambda_{0}=0$, reject the null hypothesis. However, the restriction $\lambda_{0}=0$, is rejected only for models for advanced economies. The hypothesis is not rejected for emerging economies. The statistical significance of the model with break in the US common factor for advanced economies indicates a shift in the interdependence among advanced markets during the crisis period. This is not the case with emerging markets where we do not find changes in interdependence.

The restriction $\varphi_{1, j}=0$, results in a rejection of the null hypothesis. This test suggests that model estimation without contagion parameters may suffer from misspecification. As this test also approximates the test for a joint hypothesis of no contagion, the rejection of the null hypothesis suggests evidence of significant contagion running from the US to other markets during the global financial crisis. When a formal LR test is performed for a joint test of statistical significance of the contagion parameter estimates $\left(\varphi_{1, j}=0\right)$ in Eq. (18), we reject the null hypothesis providing statistical evidence of financial contagion in advanced and emerging markets (running from the US market) during the GFC. The result is reported in Table 3 Panel B. 


\subsection{Measuring contagion effects - Volatility decomposition}

The unconditional volatility decomposition estimates for total equity market returns from the latent factor model for the US and the four advanced economies and four emerging economies are presented in Table 4. During the non-crisis period, the common factor explains a large portion of equity market volatility for advanced economies, particularly, among the European countries. This could be due to the fact that the European countries have similar institutional frameworks to the European Union and therefore markets are more integrated. The results for the crisis period show that the common factor accounts for about 54 percent of the US equity market, about 27 percent (each) of the French, Japanese and British equity markets, and about 17 percent for the German equity market. The country specific idiosyncratic factors contribute less to the volatility (except for Japan) suggesting lower portfolio diversification benefits for international investors.

During the crisis period, contagion factors are the dominant in explaining the volatility of the French, German and British equity markets. The contagion effects running from the US alone explain about 73 percent of the volatility of French, 77 percent of the volatility of German and 65 percent of the volatility of British equity markets. The greater contagion effects in European equity markets can be attributed to panic among investors about the effect of the US crisis (in terms of size and influences) in European markets.

Among the advanced countries, the Japanese equity market experiences less contagion effects from the US equity market (US shocks explain about 19 percent of the volatility of the Japanese equity market). Wei (2009) argues that Japanese markets during the crisis period were facing economic problems and a natural disaster (typhoon) and the Japanese media were focusing on those issues rather the crisis in the US. Within country attention in Japanese markets is also reflected in the contribution of the country-specific idiosyncratic factor to total equity market volatility (the idiosyncratic factor explains about 54 percent volatility of Japanese equity market). This finding supports the information channel argument of financial contagion (King and Wadhwani, 1990).

In the case of emerging markets, the common factor accounts for much less volatility in emerging markets (except for Brazil). The emerging markets investigated have very different institutional settings, and therefore might have less commonality in terms of explaining equity market returns. Contagion effects from the US equity market to emerging markets show that Brazilian and Chinese equity markets experience lower contagion effects from the US than other emerging markets in our 
sample. The US shocks (contagion) explain about 21 and 29 percent of the volatility of these markets respectively. However, US shocks explain about 57 percent of the Russian equity market volatility. Surprisingly, the Indian equity market experienced the greatest contagion effect from US equity market among all the countries investigated.

During the global financial crisis, the financial sector was the first most affected segment of the economy. We are interested in contagion effects from the US financial sector to the financial sector of other advanced economies and emerging economies. Table 5 shows that although equity market in advanced countries experience larger contagion effects from the US equity market in total, the financial sector in advanced countries (except Japan) do not experience contagion effects from the US financial sector. The US financial sector shocks explain about 4 percent of the volatility of the French financial sector, 6 percent volatility of the German financial sector and about 2 percent of the UK financial sector. There could be several reasons behind this. The financial markets in the US and Europe are more integrated and have strong financial linkages (cross-boarder lending and borrowing, and FDI and FPI). As a result, investors rationally assume that financial markets in Europe may suffer from the similar problems, and behave accordingly. This may lead to the transmission of crisis through financial linkages (although we do not formally test for financial linkages for crisis transmission in this paper). Unlike the aggregate equity market, the Japanese financial sector experiences large shocks from the US financial sector. The US shocks explain about 70 percent of the volatility, although the Japanese financial sector is assumed to be more resilient to external influences (Kawai and Takagi, 2009).

While considering the contagion effects of the US financial sector in emerging markets, we find similar results as in equity market contagion. Shocks from the US financial sector explain about one quarter of Brazilian financial sector volatility and about one third of Chinese financial sector volatility. The Indian financial sector experiences more contagion effects. The US financial sector shocks explain about 74 percent of the volatility during the crisis period.

For further reference, we transform the results in Table 4 and 5 into their squared basis point equivalent by multiplying these results by the variance on the returns on market index for each country. The estimated variance decompositions in squared basis points are reported in Table 6 . This transformation of results quantifies the contagion effects in a meaningful way. It also helps to reduce the ambiguity of percentage basis expression in cross-market comparisons. For example, the US shocks explain 70 percent of the volatility of the Japanese financial sector returns and about 74 
percent of the volatility of the Indian financial sector return. However, the magnitude of effects on squared basis point in Indian financial sector is about twice the effects on Japanese financial market.

In squared basis points, the US contagion contributes to increase in the variance of UK equity market by 3.961 squared basis points which is greatest among advanced equity markets. The US contagion shocks contribute to variance of the Japanese equity market by 0.785 square basis points. Among the emerging equity markets, the US contagion shocks contribute to a large increase in the variance of these markets, particularly in the Indian and Russian markets. The magnitude of contagion shocks in squared basis point is greater for Russian equity market than for Indian equity market, although the US contagion shocks explain larger proportion of Indian equity market volatility than the Russian equity market volatility (as shown in Table 3). The results suggest that the US contagion shocks increase the variance of Russian equity market in greater scale than that of the Indian equity market. Similarly, the US shocks increase the volatility of Brazilian equity market more than that of for the Japanese market (2.341 versus 0.785 squared basis points), although the proportion contribution of the US shocks in Japanese equity market is higher than in the Brazilian equity market.

In financial sectors, the contagion from the US financial sector accounts for about 5.5 square basis points in the total variance of Japanese financial market. The square point basis contribution of US financial sector shocks is higher for emerging financial sectors. For example, the US shocks account for about 11.5 square basis points for variance in the Indian financial sector returns and about 10.4 square basis point for variance in the Russian financial sector returns.

\subsection{Robustness and sensitivity analysis of results}

We also examined contagion from the US financial sector to the aggregate equity markets in other countries and contagion from the US equity market to financial sector of other markets. The results are consistent, i.e. the financial markets in advanced countries (except Japan) experience very small contagion effects from the US (equity market or financial sector). In addition, we considered September 15, 2008 to May 29, 2009 as the crisis period. We also performed the sensitivity analysis for geographic time differences considering (i) data as it is, that is, without time adjustment, and (ii) using the 2-day rolling over moving average (as in Forbes and Rigobon (2002)). The central results remain the same. 


\section{Concluding Remarks}

The global financial crisis has been widely characterized as beginning with the real estate bubble burst and sub-prime crisis in US. This was followed by a sharp decline in equity market indices in the US and subsequently in other countries. The crisis was not limited to advanced economies. Many emerging economies experienced even sharper decrease in stock market indices. This paper examined the contagion effects from the US to advanced and emerging economies during the global financial crisis using a latent factor model. We found significant contagion effects from the US equity market to equity markets in both advanced and emerging economies. The contagion factors were the dominant factors explaining the volatility of these markets during the crisis period. However, we found less contagion effects from the US financial sector to the financial sector of advanced economies except Japan. Our results suggest that contagion effects are not strongly related to the level of global integration.

\section{References}

Aggarwal, R., C. Inclan, and R. Leal (1999). Volatility in emerging stock markets. Journal of Financial and Quantitative Analysis 34(1), 33-55.

Bae, K. H., A. Karolyi, and R. Stulz (2003). A new approach to measuring financial contagion. Review of Financial Studies 16(3), 717-763.

Baig, T. and I. Goldfajn (1999). Financial market contagion in the Asian crisis. Staff Papers International Monetary Fund 46, 167-195.

Baur, D. G. (2012). Financial contagion and the real economy. Journal of Banking and Finance 36(10), 2680-2692.

Bekaert, G., M. Ehrmann, M. Fratzscher, and A. J. Mehl (2011). Global crises and equity market contagion. Working Paper 17121, National Bureau of Economic Research.

Bekaert, G. and C. R. Harvey (1995). Time-varying world market integration. Journal of Finance 50(2), 403-444.

Bekaert, G., C. R. Harvey, and A. Ng (2005). Market integration and contagion. Journal of Business 78(1), 39-70. 
BIS (2009). The international financial crisis: timeline, impact and policy responses in Asia and the Pacific. Technical report, Bank for International Settlements.

Corsetti, G., M. Pericoli, and M. Sbracia (2005). Some contagion, some interdependence: More pitfalls in tests of financial contagion. Journal of International Money and Finance 24(8), 11771199.

Diamond, D. W. and P. H. Dybvig (1983). Bank runs, deposit insurance, and liquidity. Journal of Political Economy 91(3), 401-419.

Dornbusch, R., Y. C. Park, and S. Claessens (2000). Contagion: Understanding how it spreads. World Bank Research Observer 15(2), 177-197.

Dungey, M., R. Fry, B. Gonzalez-Hermosillo, and V. Martin (2005). Empirical modelling of contagion: a review of methodologies. Quantitative Finance 5(1), 9-24.

Dungey, M. and V. Martin (2001). Contagion across financial markets: An empirical assessment. New York Stock Exchange Conference Paper, 16-17.

Eichengreen, B., A. Rose, and C. Wyplosz (1996). Contagious currency crises: First tests. Scandinavian Journal of Economics 98(4), 463-484.

Forbes, K. J. and R. Rigobon (2002). No contagion, only interdependence: Measuring stock market comovements. Journal of Finance 57(5), 2223-2261.

Glick, R. and A. K. Rose (1999). Contagion and trade: Why are currency crises regional? Journal of International Money and Finance 18(4), 603-617.

Goldstein, M. (1998). The Asian Crisis: Causes, Cures, and Systematic Implications. Institute for International Economics.

Hamao, Y., R. Masulis, and V. Ng (1990). Correlations in price changes and volatility across international stock markets. Review of Financial Studies 3(2), 281-307.

Inclan, C. and G. C. Tiao (1994). Use of cumulative sums of squares for retrospective detection of changes of variance. Journal of the American Statistical Association 89(427), 913-923.

Kaminsky, G., S. Lizondo, and C. M. Reinhart (1998). Leading indicators of currency crises. Staff Papers - International Monetary Fund 45(1), 1-48. 
Kaminsky, G. and C. Reinhart (1998). Financial crises in Asia and Latin America: Then and now. American Economic Review 88(2), 444-448.

Kawai, M. and S. Takagi (2009). Why was Japan hit so hard by the global financial crisis? Working Paper Series 153, Asian Development Bank Institute.

King, M. and S. Wadhwani (1990). Transmission of volatility between stock markets. Review of Financial Studies 3(1), 5-33.

Kodres, L. E. and M. Pritsker (2002). A rational expectations model of financial contagion. Journal of Finance 57(2), 769-799.

Masson, P. (1999). Contagion: Macroeconomic models with multiple equilibria. Journal of International Money and Finance 18(4), 587-602.

Mondria, J. and C. Quintana-Domeque (2012). Financial contagion and attention allocation. Economic Journal, 1-26.

NBER (2010). Business cycle dating committee report. Technical report, National Bureau of Economic Research.

Pasquariello, P. (2007). Imperfect competition, information heterogeneity, and financial contagion. Review of Financial Studies 20(2), 391-426.

Rijckeghem, C. V. and B. Weder (2001). Sources of contagion: Is it finance or trade? Journal of International Economics 54(2), 293-308.

Sanso, A., V. Arago, and J. L. Carrion (2004). Testing for changes in the unconditional variance of financial time series. Revista de Economia Financiera 4, 32-53.

Wang, K. M. and T. B. Nguyen Thi (2012). Did China avoid the Asian flu? The contagion effect test with dynamic correlation coefficients. Quantitative Finance 23(3), 471-481.

Wei, L. T. (2009). Combating the global economic crisis: Japan's policies and politics. Technical Report EAI Background Brief No. 436, East Asian Institute, National University of Singapore.

Yuan, K. (2005). Asymmetric price movements and borrowing constraints: A rational expectations equilibrium model of crises, contagion, and confusion. Journal of Finance 60(1), 379-411. 


\section{School of Economics and Finance Discussion Papers}

2013-15 Equity market Contagion during the Global Financial Crisis: Evidence from the World’s Eight Largest Economies, Mardi Dungey and Dinesh Gajurel

2013-14 A Survey of Research into Broker Identity and Limit Order Book, Thu Phuong Pham and P Joakim Westerholm

2013-13 Broker ID Transparency and Price Impact of Trades: Evidence from the Korean Exchange, Thu Phuong Pham

2013-12 An International Trend in Market Design: Endogenous Effects of Limit Order Book Transparency on Volatility, Spreads, depth and Volume, Thu Phuong Pham and P Joakim Westerholm

2013-11 On the Impact of the Global Financial Crisis on the Euro Area, Xiaoli He, Jan PAM Jacobs, Gerald H Kuper and Jenny E Ligthart

2013-10 International Transmissions to Australia: The Roles of the US and Euro Area, Mardi Dungey, Denise Osborn and Mala Raghavan

2013-09 Are Per Capita $\mathrm{CO}_{2}$ Emissions Increasing Among OECD Countries? A Test of Trends and Breaks, Satoshi Yamazaki, Jing Tian and Firmin Doko Tchatoka

2013-08 Commodity Prices and BRIC and G3 Liquidity: A SFAVEC Approach, Ronald A Ratti and Joaquin L Vespignani

2013-07 Chinese Resource Demand and the Natural Resource Supplier Mardi Dungy, Renée Fry-McKibbin and Verity Linehan

2013-06 Not All International Monetary Shocks are Alike for the Japanese Economy, Joaquin L Vespignani and Ronald A Ratti

2013-04 Chinese Monetary Expansion and the US Economy, Joaquin L Vespignani and Ronald A Ratti

2013-03 International Monetary Transmission to the Euro Area: Evidence from the US, Japan and China, Joaquin L Vespignani and Ronald A Ratti

2013-02 The impact of jumps and thin trading on realized hedge ratios? Mardi Dungey, Olan T. Henry, Lyudmyla Hvozdyk

2013-01 Why crude oil prices are high when global activity is weak?, Ronald A Rattia and Joaquin L Vespignani

Copies of the above mentioned papers and a list of previous years' papers are available from our home site at http://www.utas.edu.au/economics-finance/research/ 